\title{
USE OF A RADIO-ACTIVE TRACER FOR THE MEASUREMENT OF SEDIMENT TRANSPORT IN THE NETHERLANDS
}

\author{
J.N. Svasek and H. Engel \\ Engineers, Hydraulic Division of the Delta- \\ works, Rijkswaterstaat, The Hague.
}

\section{INTRODUCTION}

The "Rijkswaterstaat" has developed a method based on the use of radio-active tracers for the evaluation of sediment transport due to the combined action of waves and currents.

The results of preparatory studies and a laboratory test were published in a previous report by J.J. Arlman, P. Santema and J.N. Svasek $[1]$.

The main principles of the method were

1. Detection by a sledge-mounted unit towed by a surveyvessel and continuous registration on board of the radio-activity measured on the sea botton.

2. Employment of low specific radio-activity of tracer material and a large quantity thereof.

3. Use of a long-life isotope and high radio-activity.

4. Measurement of the vertical distribution of radioactivity in core samples or if possible by discrimination.

In March 1958 the first lot of tracer material was placed on the sea bed. The tracer material consisted of the radio-active isotope Scandium 46 emitting 2 curies incorporated in $100 \mathrm{~kg}$ "greensand". Scandium 46 has a half-life of 84 days and emits strong gramma radiations with energies of 0.89 and $1.12 \mathrm{MeV}$.

Afterwards, in 1959, two series of measurements were taken near the entrance to the Rotterdam Waterway. Four droppings formed one series; they were generally carried out in the following manner: $50 \mathrm{~kg}$ greensand labeled with 2 Curies Scandium was dropped in 4 places at a safe distance from each other. 2 of the 8 portions consisted of smaller quantities of both radio-activity and greensand.

In the following paragraphs the preparation, dropping and detection of the tracer, the working out of the registrations and the interpretation of the results of the 1959 measurements are discussed.

\section{PREPARATION, DROPPING AND DETECTION}

The scandium hydroxyde for one dropping (approx. $1.5 \mathrm{gr}$ ) is packed in a quartz tube and an aluminium can and irradiated in a reactor for about 4 weeks. On arrival at the place where the tracer is prepared the cans are taken out of their transport containers and stored temporarily.

The tracer material ("greensand") is an ionexchanger with a specific weight of 2.77 which approaches the specific weight of the sea-bed material (2.67) and is given sufficient hardness by 
COASTAL ENGINEERING

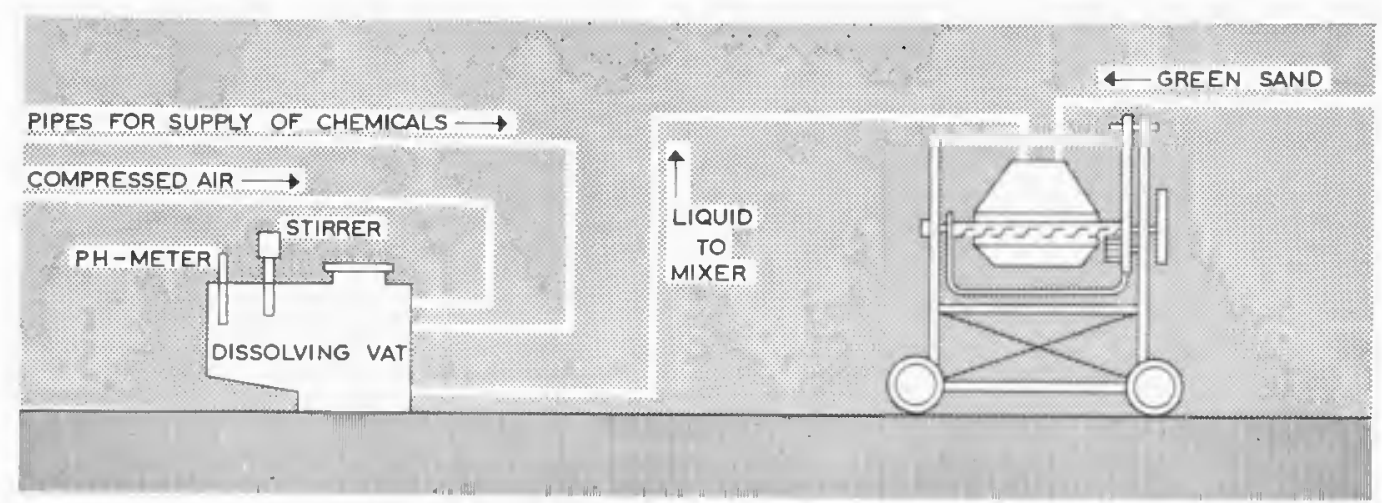

Fig. 1. Dissolving vat and mixer.
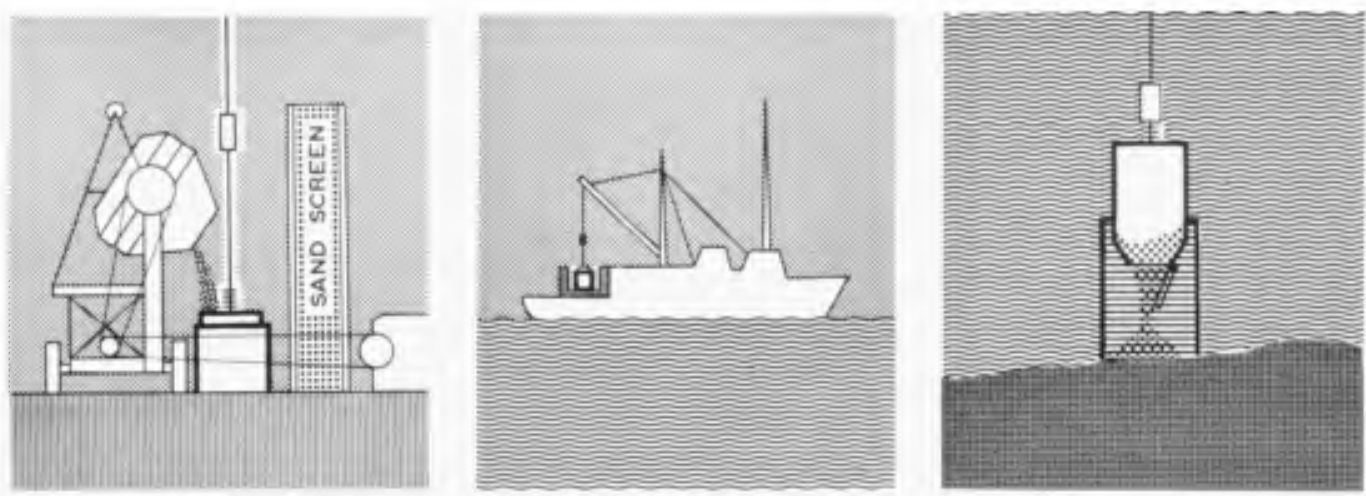

Fig. 2. Transport and injection of the tracer material.
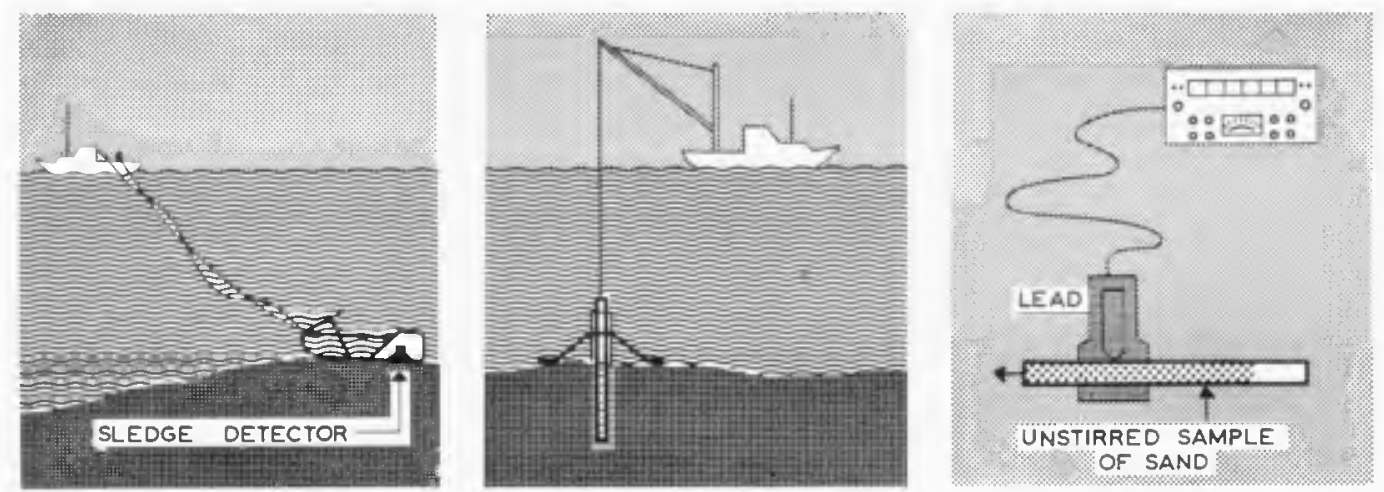

Fig. 3. Detection of tracer distribution. 


\section{USE OF A RADIO-ACTIVE TRACER FOR THE MEASUREMENT OF SEDIMENT TRANSPORT IN THE NETHERLANDS}

roasting at $700^{\circ} \mathrm{C}$.

For one dropping $50 \mathrm{~kg}$ of this material is mixed with a solution containing trivalent $S$ candium ions. The solution is made in a special vat were the aluminium can and the tube are broken open under concentrated nitric acid. After dissolving for a time the liquid is neutralised and aluminium chloride added. Finally the solution 18 pumped into the mixer and the vat rinsed with water. The labeling takes place in the mixer (fig.1).

The ion-exchanging capacity of the greensand is so great that without the addition of trivalent aluminium ions very irregular surface labeling takes place. With the surplus of aluminium ions in the solution more reasonable labeling throughout the mass is effected:

Distribution of radio-activity in the fractions of a sample of tracer material:

\begin{tabular}{|l|c|c|c|c|}
\hline fraction & $\begin{array}{c}\text { weight } \\
\text { percentage }\end{array}$ & \multicolumn{2}{|c|}{ Calculated activity percentage } & $\begin{array}{l}\text { measured } \\
\text { activi ty } \\
\text { percentage } \\
\text { in sample }\end{array}$ \\
\hline $300-420 \mu$ & 0.1 & 0.1 & 0.0 & 0.1 \\
$210-300 \mu$ & 2.9 & 2.9 & 1.3 & 2.8 \\
$150-210 \mu$ & 45.1 & 45.1 & 29.8 & 36.0 \\
$105-150 \mu$ & 21.5 & 21.5 & 20.0 & 21.6 \\
$75-105 \mu$ & 16.3 & 16.3 & 21.6 & 19.7 \\
$50-75 \mu$ & 14.1 & 14.1 & 27.1 & 19.7 \\
\hline
\end{tabular}

When the cans of radio-active scandium are stored and afterwards when they have to be placed in the dissolving vat handling is done by one man unsheilded at a distance of 2 mtrs, but only for a few seconds. The remaining work is done from behind a sand barrier where the radiation does not exceed the permitted level for 24 hours daily.

The maximum radiation received by one man in a week during the storing and preparing of 4 portions each containing 2 Curies of radio-activity was $75 \mathrm{mR}$, while $300 \mathrm{mR}$ a week is permitted by law for 52 weeks per year.

From the mixer the tracer is poured into the injection device and placed on board the transport vessel. The injection device was modified several times during the experiments. In the perfected apparatus the tracer is lowered in a container that can be opened by means of a falling weight. After leaving the container the tracer material settles within a cylindrical screen. This screen is attached to the container in such a way that it stays on the bottom while the container follows the movement of the vessel (fig.2).

After the dropping operation the container is decontaminated with a strong jet of water and checked for radio-activity rith a hand monitor. 
The placing of the material on the sea bed can be carried out only when circumstances are favourable (no swell, wind waves not higher than $40 \mathrm{~cm}$., current velocities below $40 \mathrm{~cm} / \mathrm{sec}$ ).

The movement of the radio-active material on the sea bed was followed chiefly by means of a sensitive scintillation detector mounted on a sledge (fig.3). The detector was protected against shocks by a foam rubber covering $18 \mathrm{~mm}$ thick.

Nevertheless, heavy hocks do show in the registration.

The 6-core cable between the scintillation detector and the registration instruments on board the towing survey launch proved to be very vulnerable. An experiment in which towing cable and electric cable were combined in one armoured cable was unsuccessful.

A stand-by detection unit was built because changing the six core cables took about a day and days suitable for working at sea are rare. This detection unit consisted of 24 Geiger-Müller tubes placed in a sledge similar to the one carrying the scintillation detector. The tubes are protected with foam-rubber and the power supply ( 15 batteries) for three months is built into the sledge. A one-core coaxial cable connects the detector with the instruments on board. Repairs to or change of cables can be carried out on board within half an hour.

The background detected by the scintillation detector increases as a result of the natural activity of the bottom sediment from $100 \mathrm{c} . \mathrm{p} . \mathrm{m}$ at $5 \mathrm{~cm}$ above the bottom to $300 \mathrm{c.p} . \mathrm{m}$ on the bottom. Outside the tracer area we can also check whether the survey launch is not travelling too fast. This checking is not possible with a Geiger-Müller detector, however, because of its low sensitivity to the radio-activity of the bottom sediment. For good navigation it proved necessary to maintain a speed of about $1.2 \mathrm{~m} / \mathrm{sec}$.

The vertical distribution of the tracer in the sea bed was investigated in unstirred samples. The pneumatic sampling apparatus used during the first experiments proved to be too complicated for routine sampling. It was replaced by a simple mechanical device that produce about 6 samples a day with an average length of $0.80 \mathrm{~m}$.

Supplementary samples were taken with a Van Veen Grab. Both kinds of sample were analysed in the laboratory. Due to absorption in the sample and the low rate of radio-activity available, relatively few of the samples showed a significant distribution pattern. No tracer material was found more than $10 \mathrm{~cm}$ below the sea bed (fig.4).

The maximum activity in a core sample $7 \mathrm{~cm}$ in diameter was $0.43 \mathrm{c}$, but most of them had less than $0.15 \mathrm{C}$.

A laboratory experiment was carried out to find out whether it is possible to get information concerning the depth of the tracer below the sea-bed by using a channel discriminator to measure the 2 emitted $\gamma$ radiations $(0.89$ and $1.12 \mathrm{MeV})$ separately. [1] (page.38) This turned out to be impossible due to the fact that the $1.12 \mathrm{MeV} \gamma$ 's transfer part of their energy to the electrons of the absorber. The photon is deflected from its original course 


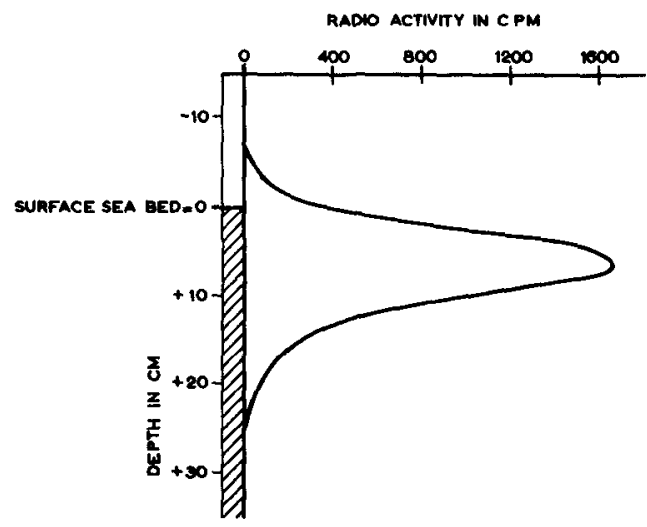

Fig. 4. Vertical distribution of tracer at one point.

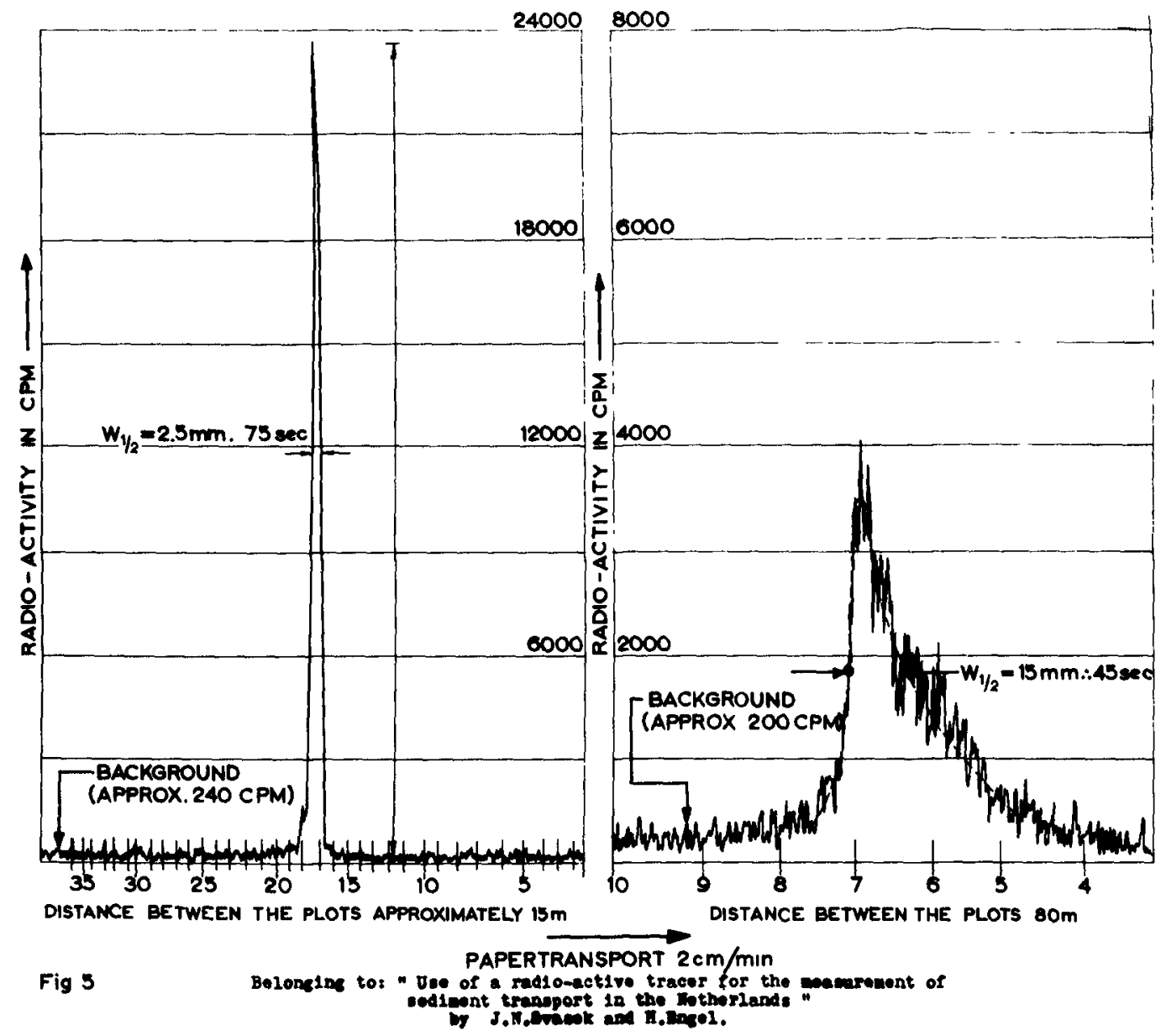

Fig. 5. Examples of registration of radio-activity of the sea-bed. 


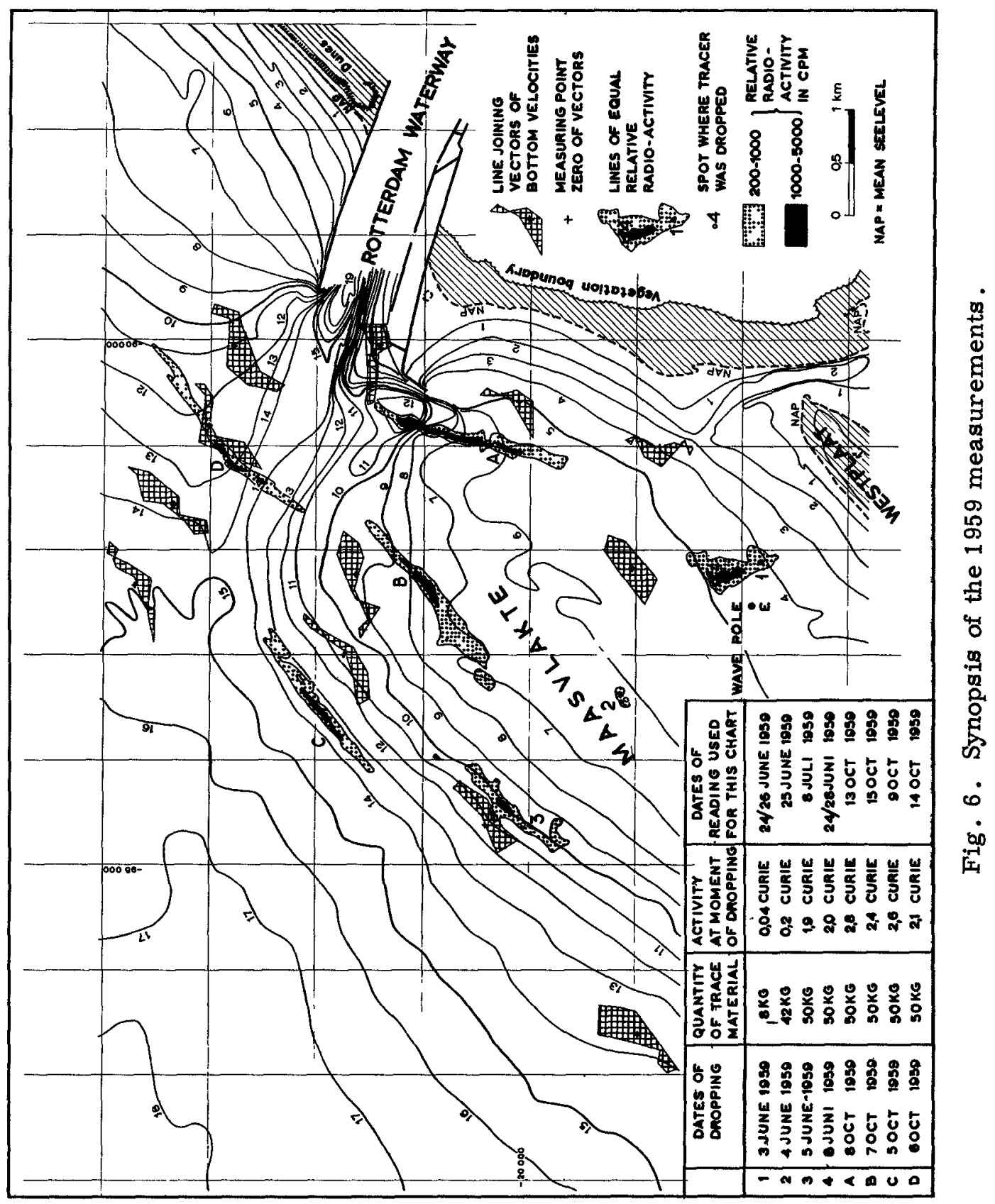




\section{USE OF A RADIO-ACTIVE TRACER FOR THE MEASUREMENT OF SEDIMENT TRANSPORT IN THE NETHERLANDS}

and degraded in energy so that the photo-peak of the $0.89 \mathrm{MeV} \gamma / \mathrm{s}$ is not measurable (Compton effect).

The position of the survey launches during readings was fixed with the help of a Decca Survey System. The error in the area investigated seemed to be less than $10 \mathrm{~m}$. Detection lines were chosen spaced 40 to 150 mtrs apart.

\section{WORKING OUT THE REGISTRATIONS}

Before dropping the tracer material the background of the area in which measurements were to be carried out was scanned with the sledge detector.

As a rule these measurements showed a background varying roughly between 200 and $300 \mathrm{c.p} \cdot \mathrm{m}$ for the scintillation unit and between 130 and $200 \mathrm{c.p} . \mathrm{m}$ for the Geiger-Müller detection unit. The response factors of the detectors for a thin layer of radioactivity on the surface were $0.29 \cdot 10^{-5} \mathrm{mC} / \mathrm{m}^{2}$ per c.p.m and 0.54 .105 $\mathrm{mC} / \mathrm{m}^{2}$ per c.p.m respectively for Scandium 46 . Consequently, the equivalent initial radio-activity of the sea bed was $0.58-0.87$ $\mu \mathrm{C} / \mathrm{m}^{2}$ for the Scintillation unit and $0.70-1.08 \mu \mathrm{C} / \mathrm{m}^{2}$ for the GeigerMüller detection unit.

The total activity along a line is obtained by subtracting the background from the integration of the activity registered (fig.5) and multiplying it by the speed of the boat.

The maximum level of radio-activity remains below the real value because of the time constant $T$ of the ratemeter. When the width of the radio-activity peak registered at half its height $W_{\frac{1}{2}}$ is more than 4 times the time constant the difference remains below 20\%. In our experiments this width was nearly always more than $8 \mathrm{sec}$ and $T=1$ sec. so no corrections for the height of the peak were necessary.

\section{INTERPRETATION OF THE RESULTS}

In 1959 two series of simultaneous measurements were carried out for the purpose of investigating the main direction of the sand movement in the area around the entrance of the Rotterdam Waterway and the piers projected for the Europoort, the new harbour for supercargo vessels (fig.6).

In the first series various combinations of tracer quantity and radio-activity were placed on the Masvlakte, a relatively shallow, faintly sloping area. It is generally supposed that the Massvlakte is the main supplier of the sand that settles in front of and in the entrance to the Waterway. This sand, (about 800,000 $\mathrm{m}^{3}$ a year) has to be dredged away continuously.

Figure 6 shows that only at points 3 and 4 the combination of tracer and radio-activity has been satisfactory. In both cases detection of tracer distribution proved to be possible 110 days after injection ( $f i g .7$ ). The limit of significance lay not more than some 600 mtrs from point 4 and 750 mtrs from point 3 .

The influence of waves on sediment transport showed only at points 4 and 1 . The tracer was at these points transported in two 
COASTAL ENGINEERING
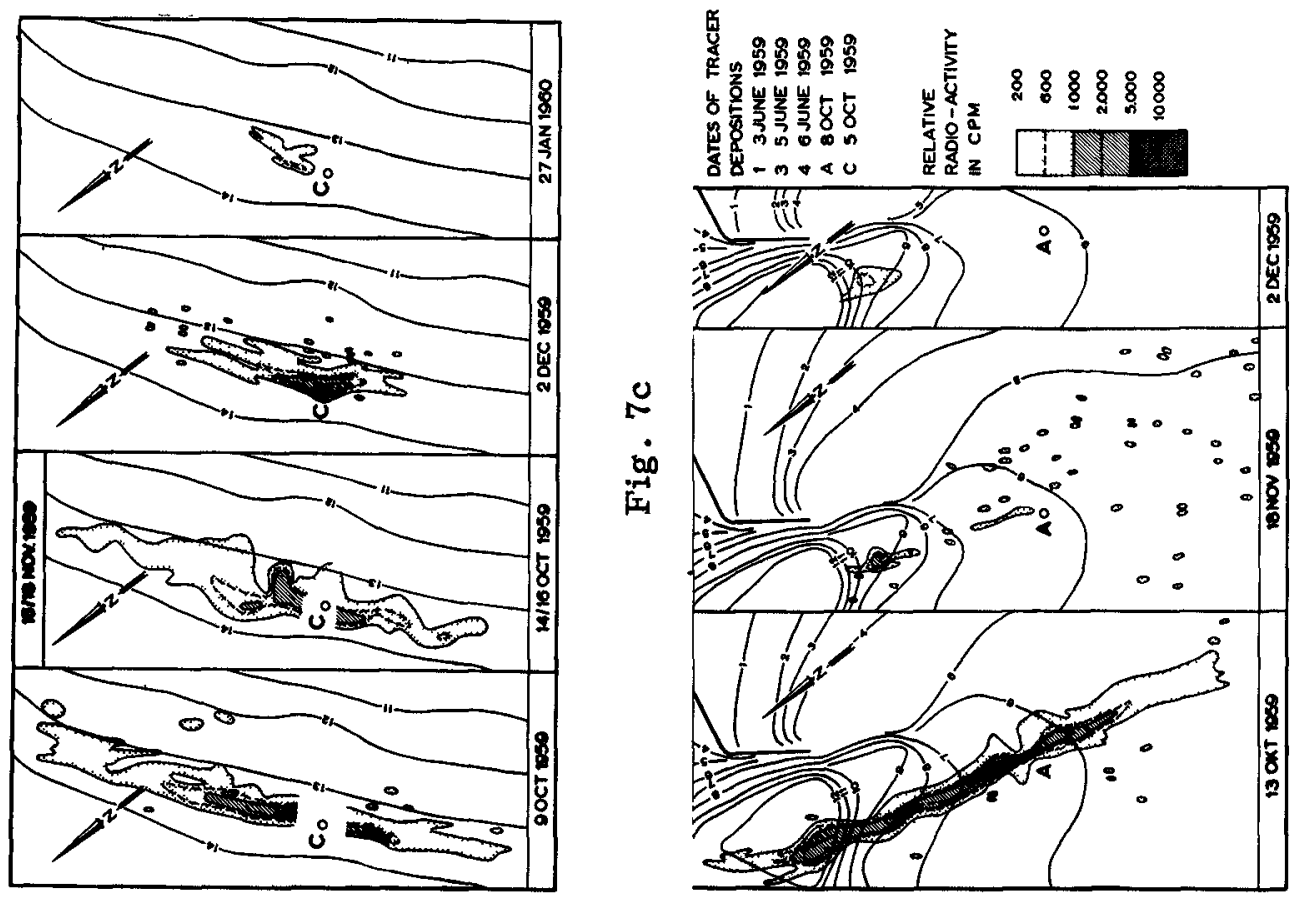

Do
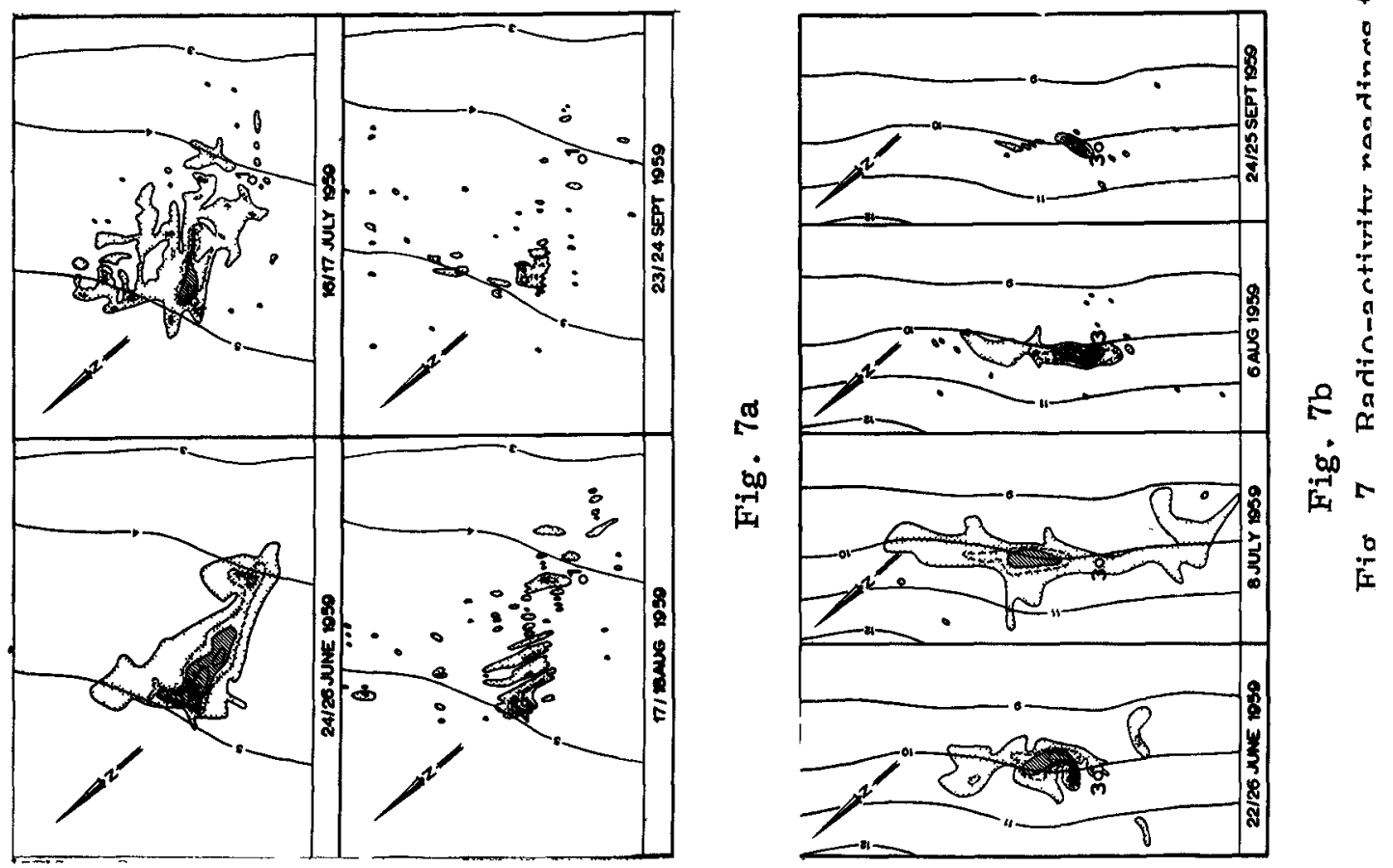

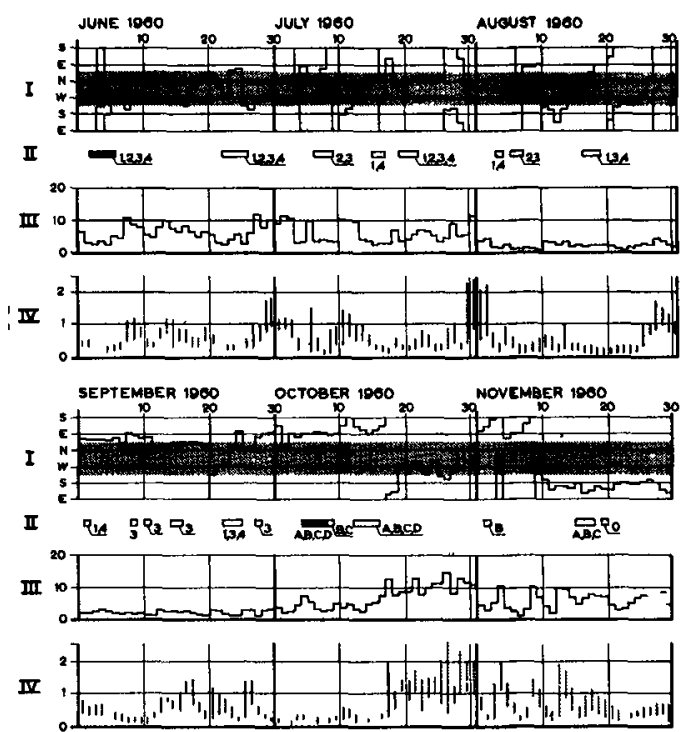

I WIND DIRECTION ( AREA OF WINDS WITH LANDWARD COMPONENTS )

II DATES AND POINTS OF DEPOSITE (س) AND READING(ש)

III WIND VELOCITY IN MTR PER SEC

II | RANGE OF SIGNIFICANT WAVE HEIGHTS REGISTERED

AT WAVE POLE E IN MTR

AT WAVE POLE E IN MTR
RANGE OF SIGNIFICANT WAVE HEIGHTS AT WAVE POLE E

RANGE OF SIGNIFICANT WAVE HEIGHTS AT WAVE POLE E
IN MTR DERIVED FROM DATA OF LIGHT VESSEL "GOEREE"

Fig. 8. Wind and wave data in the period in which readings were taken.
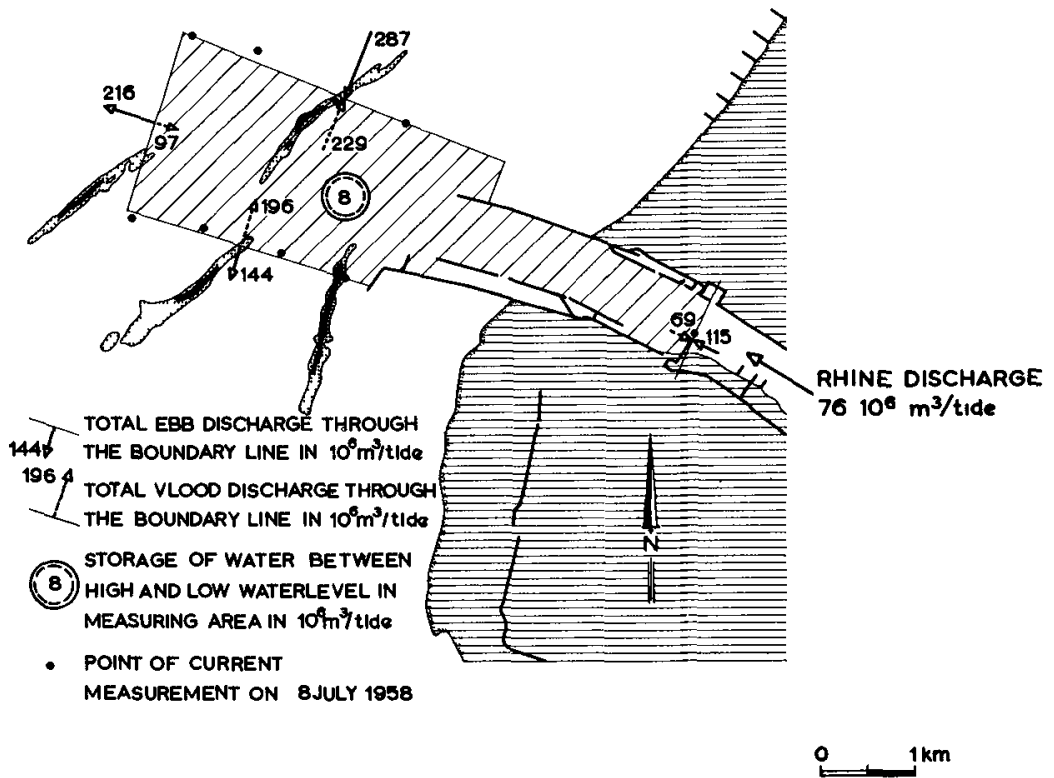

Fig. 9. Balance of current discharges at the entrance to the Rotterdam Waterway. 
main directions, parallel to the contours by the current and in the direction of the Westplaat sandbank. During the period in which readings were taken the maximum significant wave height was 2 mtrs at the wave-pole E (fig.8).

In consequence of the results of the first series a second series of experiments was carried out in the same area (points $A$ to D) with $50 \mathrm{~kg}$ tracer labeled with about 2 Curies Scandium 46 per point.

A wave height of $2 \mathrm{mtrs}$ at pole was also registered in this period. The influence of these waves makes itself felt at point $A$ and only above the contour of mean sea level minus 6 mtrs, while on the whole the waves are higher at point $A$ than they are near pole. $\mathrm{E}$.

The most important conclusion with regard to sand movement in the area is this, that the direction of transport in depths of over $6 \mathrm{mtrs}$ is not influenced by the most common wave heights.

The current pattern in the vicinity of the entrance of the Rotterdam Waterway is rather complicated. The main tidal current parallel to the coast is strongly influenced by the currents passing in and out of the Rotterdam Waterway, which also discharges a large quantity of the fresh water of the river Rhine into the North Sea (fig.9). Nevertheless, the diffusion of the tracer is mainly parallel to the coast. Moreover, the shape of the lines joining points of equal radio-activity show but small diffusion perpendicular to the main transport direction. There was no significant prevalence of transport in either tidal direction. The concentration of tracer material in the dip just beside the southern breakwater is remarkable (fig.7d). The frequent changes in depth of this dip (mostly about 2 mtrs in six months) lead to the hypothesis that the material dredged in the entrance to the Waterway comes mainly from the shallow areas beside it and that the deep places in front of the breakwaters serve as temporary storage accommodation.

Of course this hypothesis has to be checked very carefully by means of supplementary measurements near the breakwaters.

\section{CONCLUSIONS}

Measurements by tracer is still rather laborious but most technical problems concerning preparation, injection and detection have already been solved, so that the physical operations have become a matter of routine.

The results are most valuable compared with the results of soundings and current measurements. They give an impression of the direction of the bed-load transport and if more experiments are carried out simultaneously, an impression can also be obtained of the relative bed-load transport distribution in the area.

If similar tracer measurements are carried out in models and on the spot they may be of use for the interpretation of the results of the model studies.

\section{REFERENCES}

1. Progress report Rijkswaterstaat Juni 1957.

Technical Memorandum no.105, March 1958, Beach

Erosion Board. 